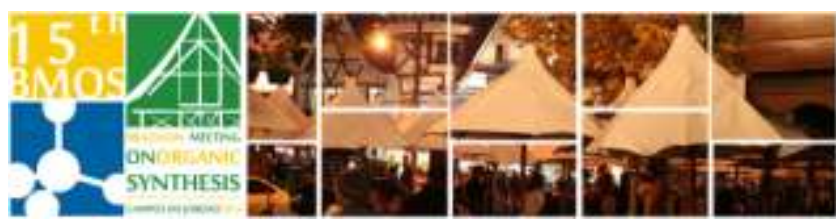

\title{
Synthesis of trifluoromethyl benzamides and their effects on the photosynthetic machinery
}

\section{Róbson Ricardo Teixeira ${ }^{*}$, Gustavo Costa Bressan ${ }^{\mathrm{b}}$, Marcus Vinícius de Andrade Barros $^{\mathrm{a}}$, and Giuseppe Forlani ${ }^{\mathrm{c}}$}

\author{
${ }^{a}$ Departamento de Química, Universidade Federal de Viçosa, Viçosa, Minas Gerais, Brazil \\ ${ }^{b}$ Departamento de Bioquímica e Biologia Molecular, Universidade Federal de Viçosa, Viçosa, Minas \\ Gerais, Brazil \\ ${ }^{c}$ Department of Life Science and Biotechnology, University de Ferrara, Ferrara, Italy \\ ${ }^{*} e$-mail corresponding author: robsonr.teixeira@ufv.br
}

Keywords: benzamides, photosynthesis, herbicides

\section{INTRODUCTION}

The use of herbicides is nowadays the most reliable and less expensive tool for weed control. Since the end of World War II, a myriad of herbicides has been brought to market to help farmers to control weed species. However, continuous application of products with the same biochemical mechanism of action has led to herbicide resistance. As a consequence, there is a constant need of new active principles to control resistant weeds

Considering the effects of several amides on the Hill reaction, ${ }^{1}$ we pursued an investigation on the effects of several trifluoromethyl benzamides on the Hill reaction. ${ }^{2}$ Herein we describe the results of this investigation.

\section{RESULTS AND DISCUSSION}

The benzamides $\mathbf{4 a}-\mathbf{m}$ were synthesized in three steps as depicted in Scheme 1.
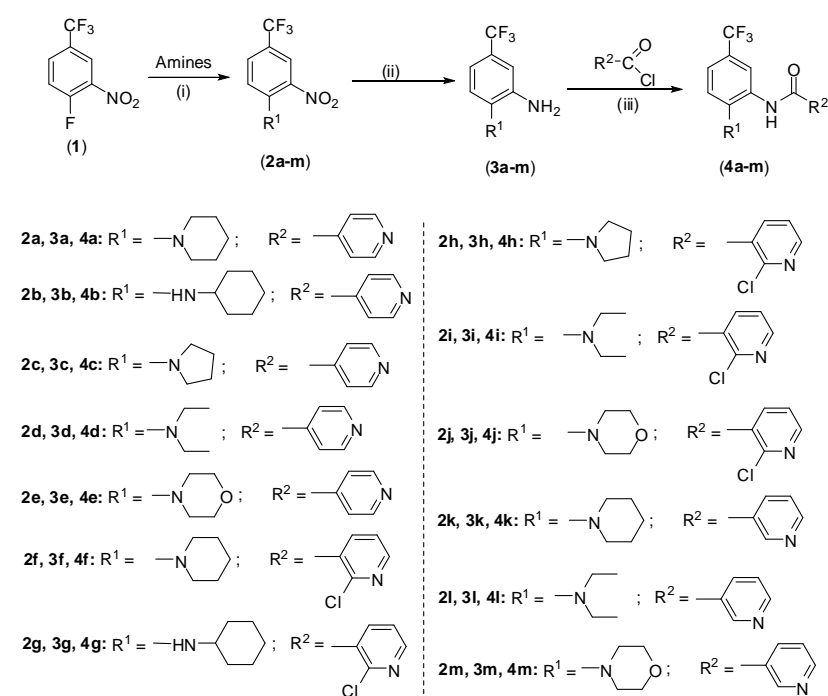

Scheme 1. Synthetic route involved in the preparation of benzamides. I) DMF, r.t.; ii) $\mathrm{SnCl}_{2} / \mathrm{HCl}$; iii) $\mathrm{CH}_{2} \mathrm{Cl}_{2}, \mathrm{Et}_{3} \mathrm{~N}$, $0{ }^{\circ} \mathrm{C} \rightarrow$ r.t.

The nucleophilic aromatic substitution between the commercially available compound $\mathbf{1}$ and appropriate amines afforded derivatives 2a-m (96-99\% yield).
Then, reduction of nitro group with $\mathrm{SnCl}_{2} / \mathrm{HCl}$ gave substances 3a-m (40-94\% yield). Acetylation reactions of compounds 3a-m with appropriated acyl chlorides afforded the benzamides 4a-m (59-91\% yield).

The effect of the compounds $4 \mathbf{a}-\mathbf{m}$ on the chloroplastic electron transport chain, measured as the light-driven reduction of potassium ferricyanide by isolated thylakoid membranes (Hill reaction), was evaluated. With the exception of compound $\mathbf{4 k}$, all substances were found to affect the Hill reaction (Table 1), being derivative $4 \mathbf{f}$ the most effective compound.

Table 1. In vitro effects of compounds $\mathbf{4 a - 4 m}$ on the Hill reaction

\begin{tabular}{|l|l|l|l|}
\hline Compound & $\begin{array}{c}\mathrm{IC}_{50} \\
\left(\mu \mathrm{mol} \mathrm{L}^{-1}\right)\end{array}$ & Compound & $\begin{array}{c}\mathrm{IC}_{50} \\
\left(\mu \mathrm{mol} \mathrm{L}^{-1}\right)\end{array}$ \\
\hline $\mathbf{4 a}$ & $26.1 \pm 4.7$ & $\mathbf{4 h}$ & $124 \pm 26$ \\
\hline $\mathbf{4 b}$ & $93.8 \pm 13.0$ & $\mathbf{4 i}$ & $19.6 \pm 4.2$ \\
\hline $\mathbf{4 c}$ & $30.9 \pm 3.2$ & $\mathbf{4 j}$ & $85.2 \pm 16.7$ \\
\hline $\mathbf{4 d}$ & $63.0 \pm 8.1$ & $\mathbf{4 k}$ & ineffective \\
\hline $\mathbf{4 e}$ & $213 \pm 86$ & $\mathbf{4 I}$ & $76.3 \pm 7.5$ \\
\hline $\mathbf{4 f}$ & $13.2 \pm 1.4$ & $\mathbf{4 m}$ & $234 \pm 136$ \\
\hline $\mathbf{4 g}$ & $115 \pm 38$ & \multicolumn{3}{|c}{} \\
\cline { 1 - 2 } & & &
\end{tabular}

\section{CONCLUSION}

A three step synthetic route was used to synthesize a series of trifluoromethyl benzamides. These compounds were effective in inhibiting the Hill reaction. Considering that several herbicides commercially available are Hill reaction inhibitors, the synthesized benzamides may represent a new scaffold to be evaluated aiming at the development of new active ingredients for weed control.

\section{ACKNOWLEDGEMENTS}

CAPES, CNPq, FAPEMIG

\section{REFERENCES}

Ware, G. W. The Pesticide Book $-5^{\text {th }}$ Ed. Fresno: Thomson Publications 2000, Chapter 11.

Teixeira, R. R.; Pereira, W. L.; Tomaz, D. C.; Oliveira, F. M. de O.; Gilberti, S.; Forlani, G. J. Agric. Food Chem. 2013, 61, 5540-5549. 